\title{
PENGARUH FRAKSI VOLUME SERAT EMPULUR SAGU (Metroxylon sp) DAN PRESENTASE ALKALI TERHADAP PENGUJIAN IMPAK SERTA ABSORPSI AIR PADA KOMPOSIT BERSERAT SAGU
}

\author{
Nevada Mario Nanulaitta, Wahyono Soeprapto, Rudy Soenoko \\ Teknik Mesin Fakultas Teknik Universitas Brawijaya \\ JI. MT. Haryono No. 167, Malang 65145, Jawa Timur-Indonesia \\ Telp. 0341-551611/ fax. 0341-565420 \\ Email:rio_nevada@yahoo.co.id
}

\begin{abstract}
Human necesities for good material to support daily activity is growing up, especially eco-friendly material. Several application such as decoration, interior, until the furniture increased along with the population growth. Sago (Metroxylon sp) as one of the plants and also as one of the staple food in Maluku, this plant thrives in Maluku. To be processed into sago that is ready to eat required the process of extraction of sago tree (Metroxylon sp) trunk that leaves waste sago pith (fiber). In this research the utilization of waste fiber sago pith in use as composite amplifier with matrix is sago starch. Research using natural ingredients as composite maker, is expected to get composite that have good impact strength and good water absorption rate. The composites were made using hand lay up method with variation of volume fraction of sago pith fiber is $30 \%$ and $50 \%$ with $\mathrm{NaOH}$ solution and aquades in alkaline process with percentage comparison of 3\%, 5\%, 7\% and 9\% for 120 minutes immersion time. The results of this study found the best impact strength on the composite with a variation of fiber volume of $50 \%$ with alkaline process $9 \%$ with the highest value on the energy absorbed composite 6,9303 (J) with impact strength $0.0693\left(\mathrm{~J} / \mathrm{mm}^{2}\right)$. The best water absorption rate is at $8.67 \%$ occurring on a $50 \%$ fiber fraction variation with a percentage of $9 \% \mathrm{NaOH}$ alkali process.
\end{abstract}

Keywords: Sago pith Fiber, Impact Strength, Water Absorption, Composite

\section{PENDAHULUAN}

Metroxylon sagu (Metroxylon sp) adalah tanaman yang menyimpan pati pada inti dari batangnya. Sagu termasuk dalam family Arecaceae-palm, Genus Metroxylon dan Spesies Metroxylon sagu hal ini di dasarkan pada kalisifikasi dari Pelayanan Konservasi Sumber Daya Alam. Penyebaran tanaman sagu di Indonesia terbesar di daerah Papua, Papua barat, Maluku dan Maluku utara dengan capaian 1,25 ha. Batang sagu berbentuk silinder dengan diameter bervariasi tergantung dengan jenis, lingkungan tempat tumbuh serta iklim. [1]

Batang pada pohon sagu (Gambar 1.) memiliki lapisan luar yang keras dan bagian dalam yang mengandung serat dan pati (Gambar 2.). Tebal kulit luar pohon sagu yang keras berkisar antara $4 \mathrm{~cm}$ sampai dengan $6 \mathrm{~cm}$; tinggi batang bervariasi tetapi pada umumnya berkisar antara 10-15 meter; dan apabila kondisi lingkungan yang baik batangnya dapat bertumbuh sampai 20 meter. [1]
Diameter batang sugu juga bervariasi tergantung pada kondisi lingkungan. Rata-rata diameternya berkisar dari $50-60 \mathrm{~cm}$; dan jika kondisi lingkungan baik diameternya bisa mencapai $80 \mathrm{~cm}$ sedankan apabila kondisi lingkungan tumbuh kurang baik; diameternya dapat mencapai $40 \mathrm{~cm} .[1]$

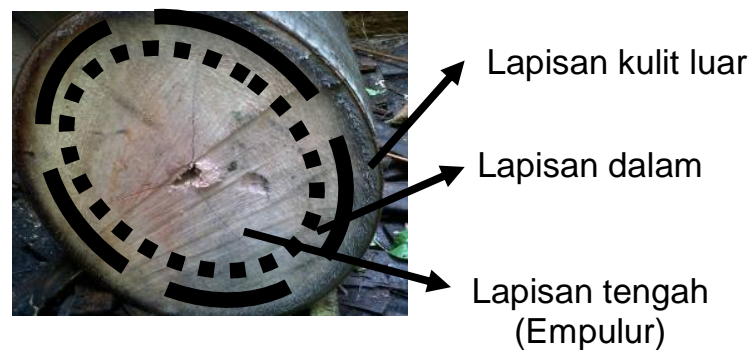

Gambar 1. Batang Pohon Sagu

Empulur sagu (lihat Gambar 3) didapatkan dari proses pengolahan batang sagu menjadi tepung sagu, dimana dalam proses tersebut diperoleh tepung dan Empulur sagu dalam perbandingan 1:6 [1]. Empulur sagu dipilih 
sebagai salah satu serat sebagai bahan penguat komposit karena ketersediaan bahan dasar serat empulur sagu yang banyak di Maluku. Jumlah serat empulur yang banyak tersebut, sampai saat ini belum di manfaatkan sebagaimana mestinya dan hanya dibiarkan menumpuk pada tempattempat pengolahan tepung sagu sehingga menyebabkan pencemaran lingkungan[1]. Selain hal itu, pembuatan komposit berbahan dasar serat empulur menjadi pilihan karena memiliki beberapa kelebihan diantaranya densitas yang rendah, bahan yang terbarukan, biaya produksi yang rendah, memiliki sifat mekanik dan fisik yang baik[2].

Penggunaan serat empulur sagu juga merupakan bagian dari pemanfaatan limbah dan mengurangi kebutuhan kayu (papan) sehingga mengakibatkan penebangan hutan yang berlebihan sehingga seiring dengan kebijakan pemerintah tentang konservasi hutan yang mengakibatkan pemanasan global (Global Warming).

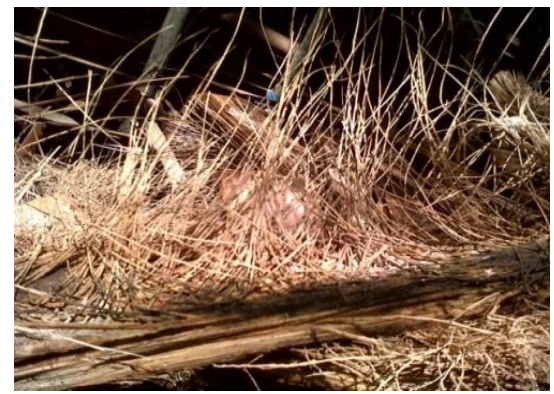

Gambar 2. Serat Sagu

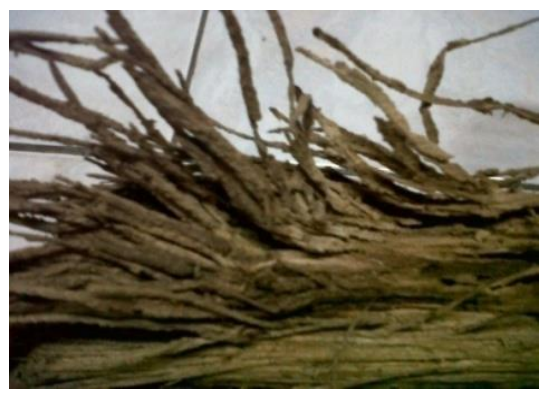

Gambar 3. Empulur Sagu

Penelitian terdahulu tentang komposit serat alam telah dilakukan. Beberapa diantaranya menggunakan matriks epoxy dengan memberikan perlakuan alkali pada serat dengan komposisi $0 \%, 5 \%, 10 \%$, dan $15 \%$ dan penggunaan volume serat sebesar $10 \%$; $20 \%$, dan $30 \%$ dari campuran. Hasil pengujian menunjukkan kekuatan impak meningkat seiring dengan peningkatan pembebanan serat dan perlakuan alkali. Kekuatan impak tertinggi didapatkan pada perlakuan alkali $10 \%$, yaitu sebesar $147 \mathrm{~J} / \mathrm{mm}^{2}$ [2].

Penelitian lain menggunakan campuran matrik dari polyester dan epoxy dengan penguat serat lontar. Pengujian yang dilakukan adalah impak, lentur dan tekan dengan variasi fraksi volume $10 \%$, $20 \%$ dan $30 \%$. Hasil pengujian menunjukkan sifat mekanis fraksi volume $20 \%$ lebih baik bila dibandingkan fraksi volume lain [3]. Pada serat alam, pengurangan lignin dapat meningkatkan interaksi serat dan resin menjadi lebih baik [4]. Selain itu, perlakuan alkali terhadap permukaan serat alam selulosa dapat mengurangi sifat hydrophilic permukaan serat sehingga memberikan kekuatan interface antara serat dan matrik menjadi optimal. Pemodifikasian proses alkali pada serat alam dapat meningkatkan mutu permukaan serat dan sifat hydrophilic. [5]

Penelitian ini difokuskan untuk meneliti pengaruh variasi fraksi volume serat dan $\mathrm{NaOH}$ sebagai media alkali terharap kekuatan impak komposit. Serat alam memiliki banyak kekurangan antara lain mudah menyerap air, tidak tahan pada suhu yang tinggi dan memiliki kekuatan rendah pada beban kejut. Keberadaan proses alkali (kimia) pada serat diharapkan mengubah sifat hydropilic serat sehingga dapat meningkatkan kekuatan komposit.

\section{METODOLOGI PENELITIAN}

Penelitian yang dilakukan adalah penelitian nyata (true experimental research) dengan tujuan mengetahaui pengaruh perlakuan alkali dengan presentasi tertentu terhadap sifat mekanis dan laju penyerapan air pada komposit.

Presentase $\mathrm{NaOH} 3 \% ; 5 \% ; 7 \%$; dan 9\% dari aquades serta perbandingan serat empulur sagu (a) dan matrik pati sagu (b) dengan variasi perbandingan $30 \%$ (a): $70 \%$ (b) dan $50 \%$ (a) : $50 \%$ (b) adalah variabel bebas. Sedangkan variabel terkontrol adalah panjang 
serat empulur sagu dan waktu perendaman pada $\mathrm{NaOH}$ adalah 120 menit.

\section{a. Alat dan Bahan}

Alat dan bahan yang digunakan pada penelitian ini adalah sebagai berikut:

- Bahan pembuatan komposit: serat empulur sagu (Gambar 2 dan Gambar 3), $\mathrm{NaOH}(3 \%, 5 \%, 7 \%$ dan $9 \%)$, pati sagu dan aquades

- Alat yang digunakan meliputi timbangan digital, mesin uji impak, cetakan spesiimen (bata), baskom,mistar, jangka sorong, cutter, gunting, kuas, spidol, sendok plasti, jam, oven.

\section{b. Prosedur pembuatan komposit}

Serat empulur sagu diambil dan dipisahkan dari empulur sagu, kemudian di bersihkan dan dikeringkan di udara terbuka. Serat melalui proses perendaman dalam suatu wadah pada larutan $\mathrm{NaOH}$ dengan konsentrasi masing-masing sebesar 3\%; $5 \% ; 7 \%$; dan $9 \%$ per liter aquades dengan waktu perendaman 120 menit.

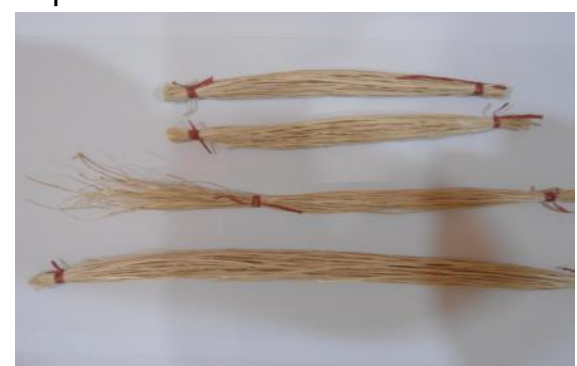

Gambar 4. Serat Umpulur Sagu setelah proses Alkalisasi

Proses alkalisasi yang dilakukan bertujuan untuk memperbaiki permukaan serat secara kimia serta membersihkan dari lapisan lignin [6]. Setelah melalui proses alkalisasi, serat di cuci dengan air bersih yang mengalir \pm 20 menit lalu di keringkan.

Proses pembuatan komposit dilakukan menggunakan metode hand lay up, dengan urutan sebagai berikut;

1. Penimbangan serat empulur sagu dan matrik pati sagu sesuai dengan fraksi volume yang di inginkan

2. Penyiapan cetakan dan Melapisi permukaan dinding cetakan dengan alumunium foil
3. Pencampuran matrik pati sagu dengan air sesuai dengan presentasi yg ditentukan

4. Tuanglah matrik ke dalam cetakan yang sudah diletakan dan di tata serat empulur sagu yang sesuai dengan fraksi volume yang di tentukan

5. Pengeringan komposit di dalam oven dengan temperatur $100^{\circ} \mathrm{C}$ selama 120 menit

6. Lakukan pengamatan pada komposit tersebut ada tidak nya void yang terjadi dengan cara menerawang lembaran komposit. Diameternya tidak lebih dari 1 $\mathrm{mm}$. Void tidak boleh mengumpal pada satu tempat (radius jarak antar void yang diizinkan adalah $1 \mathrm{~cm}$ )

7. Bentuk spesimen uji (lihat Gambar 5) sesuai dengan standar Uji Impak (ASTM D 256) dan Uji serap air (ASTM E 96).

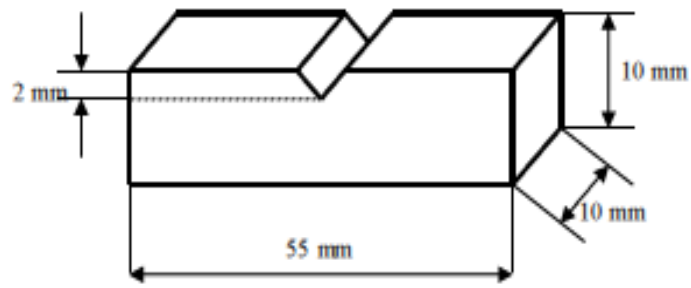

Gambar 5. Spesimen uji Impak komposit

\section{HASIL DAN PEMBAHASAN}

a. Kekuatan Impak

Dari hasil pengujian impak didapatkan data pengujian impak komposit yang bisa dilihat pada Tabel 1.

Tabel 1. Data hasil pengujian Kekuatan Impak komposit

\begin{tabular}{ccc}
\hline $\begin{array}{c}\text { Fraksi } \\
\text { Volume } \\
\text { Komposit }\end{array}$ & $\begin{array}{c}\text { Presentasi } \\
\text { NaOH } \\
(\%)\end{array}$ & $\begin{array}{c}\text { Kekuatan } \\
\text { Impak } \\
\left(\mathbf{J} / \mathbf{m m}^{2}\right)\end{array}$ \\
\hline $30 \%: 70 \%$ & 3 & 0.0327 \\
& 5 & 0.0377 \\
& 7 & 0.0417 \\
& 9 & 0.0471 \\
\hline $50 \%: 50 \%$ & 3 & 0.0457 \\
& 5 & 0.0521 \\
& 7 & 0.0608 \\
& 9 & 0.0693 \\
\hline
\end{tabular}


Hasil pengujian impak pada spesimen yang telah dilakukan proses alkalisasi dengan perbandingan $\mathrm{NaOH}$ sebesar $3 \%$, $5 \%, 7 \%$ dan $9 \%$ berbanding 1 liter aquades pada komposit dengan variasi fraksi volume 30\%:70\% menunjukkan adanya peningkatan nilai kekuatan impak rata-rata dengan presentasi $\mathrm{NaOH} 3 \%$ sebesar $0.0327\left(\mathrm{~J} / \mathrm{mm}^{2}\right)$ ke presentase $\mathrm{NaOH} 9 \%$ sebesar $0.0471\left(\mathrm{~J} / \mathrm{mm}^{2}\right)$.

Hal yang sama juga terjadi pada variasi fraksi volume komposit $50 \%$ : $50 \%$ dengan presentase $3 \% \mathrm{NaOH}$ sebesar 0.0457 $\left(\mathrm{J} / \mathrm{mm}^{2}\right)$ ke presentase $9 \% \mathrm{NaOH}$ sebesar $0.0693\left(\mathrm{~J} / \mathrm{mm}^{2}\right)$.

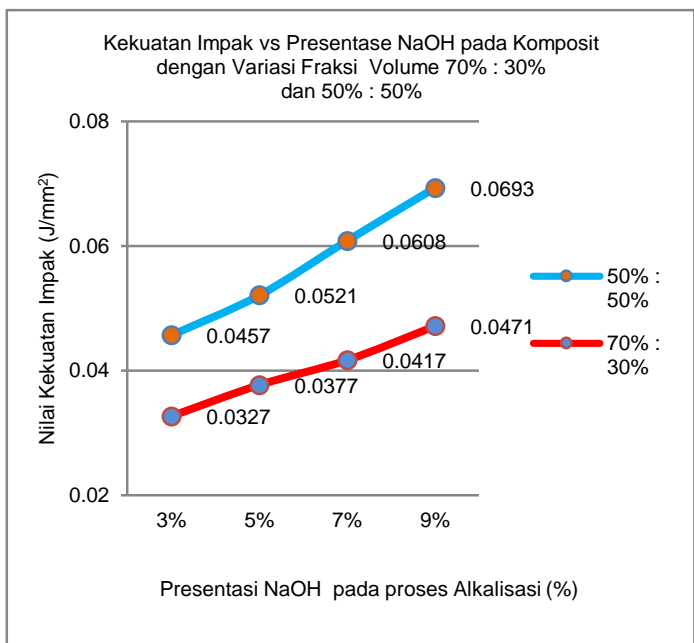

Gambar 6. Grafik Hubungan Rata-rata Kekuatan Impak vs Presentase $\mathrm{NaOH}$ pada Presentasi Variasi Fraksi Volume 70\%:30\% dan 50\%:50\%

Peningkatan kekuatan impak disebabkan karena pemodifikasian permukaan serat menggunakan $\mathrm{NaOH}$. Dengan proses alkali permukaan serat menjadi lebih baik, yaitu dengan berkurangnya lignin dan kandungan lain pada serat, sehingga mengakibatkan permukaan serat menjadi lebih kasar. Permukaan kasar ini menyebabkan kekuatan daya ikat antara permukaan serat dan matrik menjadi lebih baik.

Pengujian impak dapat dilhat dari patahan makro pada Gambar 6 dan Gambar 7. Kondisi penampang patahan pada komposit dengan variasi fraksi volume $70 \%$ matrik dan $30 \%$ serat, serta proses alkalisasi dengan kandungan $\mathrm{NaOH}$ sebesar 9\% menunjukkan ciri-ciri pola patahan brittle/getas. Yaitu kerusakan terjadi pada atu titik dan permukaan komposit tidak mengalami retak (Gambar 8).

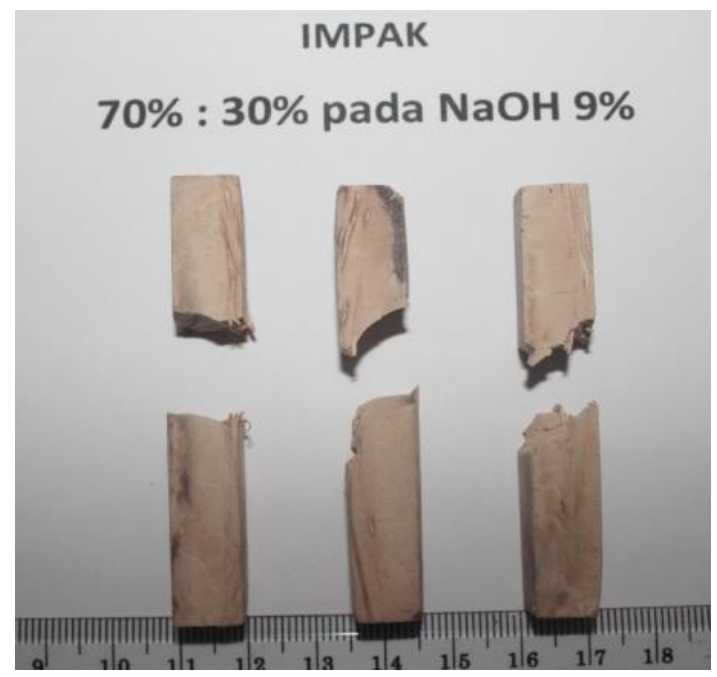

Gambar 7. Permukaan komposit pada pengujian Impak variasi fraksi volume $70 \%$ : $30 \%$ dengan proses alkalisasi $\mathrm{NaOH} 9 \%$

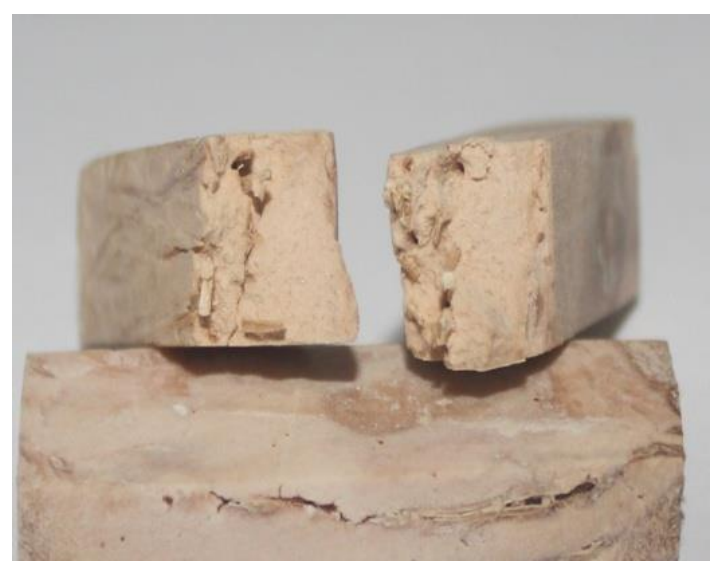

Gambar 8. Hasil patahan pada pengujian impak

Hasil pengujian impak pada komposit yaitu nilai energi serap tertinggi tertinggi berada pada komposit dengan variasi fraksi volume $50 \%: 50 \%$ dengan presentasi proses alkalisasi menggunakan $\mathrm{NaOH} 9 \%$ sebesar $6.9303(\mathrm{~J})$ dan nilai kekeuatan impak tertinggi juga pada komposit dengan fraksi volume dan 
presentase $\mathrm{NaOH}$ yang sama yaitu sebesar $0.0693\left(\mathrm{~J} / \mathrm{mm}^{2}\right)$. Dari hasil tersebut menerangkan bahwa semakin tinggi fraksi volume serat dan presentasi $\mathrm{NaOH}$ pada proses alkalisasi, menyebabkan semakin tinggi pula energi serap dan nilai kekuatan impak.

\section{b. Laju Serap Air (Absorpsi)}

Hasil pengujian presentase laju serap air pada komposit disajikan pada Tabel 2 sebagai berikut;

Tabel 2. Data hasil pengujian presentase laju serap air pada komposit

\begin{tabular}{ccc}
$\begin{array}{c}\text { Fraksi } \\
\text { Volume } \\
\text { Komposit }\end{array}$ & $\begin{array}{c}\text { Presentasi } \\
\text { NaOH } \\
(\%)\end{array}$ & $\begin{array}{c}\text { Laju Serap } \\
\text { Air (\%) }\end{array}$ \\
\hline & 3 & 8.87 \\
$30 \%: 70 \%$ & 5 & 8.91 \\
& 7 & 8.90 \\
& 9 & 8.85 \\
\hline $50 \%: 50 \%$ & 3 & 8.68 \\
& 5 & 8.70 \\
& 7 & 8.69 \\
& 9 & 8.67 \\
\hline
\end{tabular}

Laju serap air pada komposit dipengaruhi oleh pemodifikasian permukaan serat pada proses alkalisasi. Proses alkalisasi ini dapat mengurangi sifat hidrofilik pada serat alam dimana sifat hidrofilik sangat mudah menyerap kelembaban. Begitu serat alam terkena kelembaban maka ikatan hydrogen akan terbentuk antara gugus hidroksil dari molekul selulosa dan air.

Pertambahan berat komposit yang kecil mengakibatkan laju meyerapan air yang kecil juga pada komposit dan itu semakin baik buat komposit. Hal ini dapat dilihat pada Gambar 9. prosentase peningkatan berat komposit terbaik itu adalah peningkatan berat terkecil dari komposit ada pada proses alkalisasi dengan presentase $\mathrm{NaOH}$ sebesar $9 \%$ dengan fraksi volume serat sebesar $50 \%$.

\section{KESIMPULAN}

Berdasarkan hasil penelitian pada komposit serat empulur sagu bermatrik pati sagu (Metroxylon $s p$ ) dapat di tarik kesimpulan bahwa kekuatan impak tertinggi sebesar $0.0693 \quad\left(\mathrm{~J} / \mathrm{mm}^{2}\right)$ dicapai pada komposit dengan variasi fraksi volume serat $50 \%$ dengan alkalisasi $9 \% \mathrm{NaOH}$. Pengujian laju serap air (Absorbsi) pada komposit menunjukkan bahwa selisih peningkatan berat komposit terbaik sebesar $0.323(\mathrm{~g})$ dengan laju presentase peningkatan berat sebesar $8.67 \%$ terjadi pada komposit dengan variasi fraksi volume serat $50 \%$ pada proses alkalisasi $\mathrm{NaOH}$ 9\%.

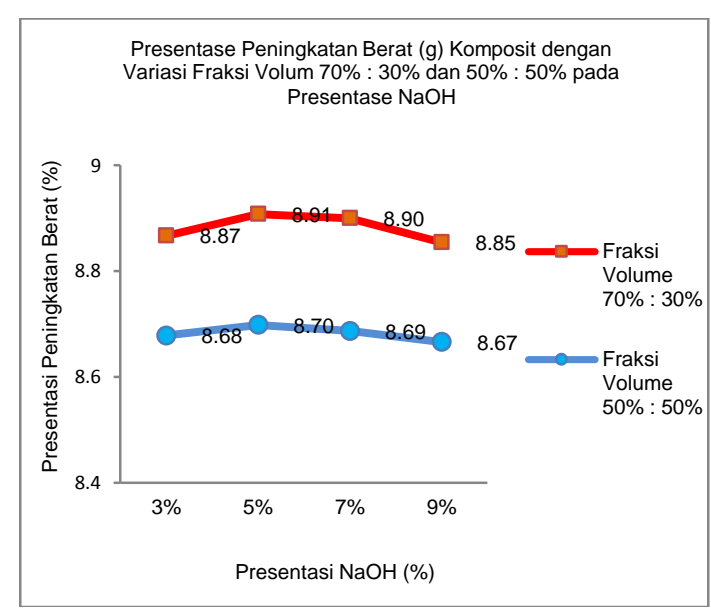

Gambar 9. Hubungan Laju Presentase Peningkatan Berat (g) Komposit dengan Variasi Fraksi Volume 70\% : 30\% dan 50\% : $50 \%$ pada Presentase $\mathrm{NaOH}$

\section{DAFTAR PUSTAKA}

[1] Rumalatu F.J, 1981., Distribusi dan Potensi Pati Sagu (Metroxylon sp) di Daerah Seram Barat (Karya Ilmiah). Bogor: Fakultas Pertanian / Kehutanan Yang Berafiliasi Dengan Fateta IPB, Bogor.

[2] Kommla.VP, OR Kanchireddy, M Shukla, T Marwala. 2013. Study on impact strength of untreated and alkali treated Napier grass fiber strands reinforced Epoxy composite, Int J Res Eng Technol 2 (3), 101-106

[3] Ghotage. P.V., 2013., Modification Flexural, Impact, Compressive Properties \& Chemical Resistance of Natural Fiber Reinforced Blend Composites. Malaysian Polymer Journal, Vol.8 No 1, p $38-44$, 2013.

[4] Onyeagaro, M (2013) Reactive Compatibilization of Natural Rubber 
(NR)/Carboxylated Nitrile Rubber (XNBR) Blends By Maleic AnhydrideGrafted-Polyisoprene (MAPI) And Epoxy Resin Dual Compatibilizers. IRJES. 2(3):7-16

[5] Bismarck. A, (2002) Surface characterization of flax, hemp and cellulose fibers; Surface properties and the water uptake behavior, Polymer Composites., Vol 23 Issue 5 (872-894)
[6] Vallo. C, JM Kenny, A Vazquez, VP (2004). Cyras Effect of chemical treatment on the mechanical properties of starchbased blends reinforced with sisal fibre.,Journal of Composite Materials 38 (16), 1387-1399. 